\title{
LA DIMENSIÓN AUTONÓMICA DE LA LIBERTAD RELIGIOSA. LA COMPETENCIA PARA LA APERTURA DE CENTROS DE CULTO
}

GERARDO RUIZ-RICO RUIZ 
SUMARIO

1. EL SILENCIO CONSTITUCIONAL SOBRE UN TÍTULO COMPETENCIAL EN MATERIA RELIGIOSA. 2. LA REGULACIÓN DEL «HECHO RELIGIOSO» EN LOS ESTATUTOS DE AUTONOMÍA. 3. LA LEY ORGÁNICA SOBRE LIBERTAD RELIGIOSA COMO MARCO NORMATIVO OBLIGATORIO DE REFERENCIA PARA LAS COMUNIDADES AUTÓNOMAS. 3.1 Contenido orgánico del derecho fundamental y posibles márgenes de intervención autonómica. 3.2 Normas de Derecho Internacional y acuerdos del Estado español con las confesiones religiosas como límites a las competencias autonómicas en materia religiosa. 4. VIABILIDAD CONSTITUCIONAL Y COMPETENCIAL PARA UNA LEGISLACIÓN AUTONÓMICA SOBRE CENTROS DE CULTO. 5. LA APERTURA DE CENTROS DE CULTO COMO UN DERECHO CONSTITUCIONAL DE CONFIGURACIÓN LEGAL SUSCEPTIBLE DE SER REGULADO POR EL LEGISLADOR AUTONÓMICO. 


\title{
LA DIMENSIÓN AUTONÓMICA DE LA LIBERTAD RELIGIOSA. LA COMPETENCIA PARA LA APERTURA DE CENTROS DE CULTO ${ }^{1}$
}

\author{
GERARDO RUIZ-RICO RUIZ \\ Catedrático de Derecho Constitucional \\ (Universidad de Jaén)
}

\section{EL SILENCIO CONSTITUCIONAL SOBRE UN TÍTULO COMPETENCIAL EN MATERIA RELIGIOSA}

La Constitución española de 1978 (CE), al consagrar la libertad religiosa como un derecho fundamental en su artículo 16, se refiere al mismo tiempo a las relaciones de colaboración con las confesiones religiosas, otorgando a una de ellas, la Iglesia Católica, una mención específica acorde con las circunstancias y el hecho religioso dominante en ese momento histórico. Esta declaración de principios y derechos no puede interpretarse sin una evidente conexión con el artículo 14 de la norma fundamental, donde se reconoce la versión formal del principio de igualdad ante la ley y se impone la prohibición sobre cualquier tipo de discriminación por razones religiosas. Pero este marco constitucional de referencia quedaría incompleto sin el condicionamiento que para cualquier regulación normativa supone la reserva material de ley

1 El autor realizó este trabajo como contribución a libro Constitución y Democracia. Ayer y Hoy. Homenaje al Profesor Torres del Moral. Por un error en el proceso de edición, no se incluyó en la citada obra. Con su publicación en esta Revista, se repara dicho error y se posibilita que el autor se sume al homenaje que 180 profesores de distintas universidades españolas y extranjeras tributaron al prof. A. Torres del Moral. 
orgánica, prevista en el artículo 81, sobre desarrollo de los derechos fundamentales y libertades públicas del Título Primero. Así pues y como punto de partida, la CE de 1978 no proporciona unos parámetros jurídicos suficientemente explícitos que permitan delimitar claramente las esferas competenciales de las que dispondrían las Comunidades Autónomas (CC.AA.), a la hora de regular diferentes aspectos que afectan al ejercicio de la libertad religiosa en su ámbito territorial ${ }^{2}$.

En primer lugar, la cláusula principal sobre la que gira el sistema de división competencial entre Estado y Comunidades Autónomas (CC.AA.) —el artículo $149 \mathrm{CE}$ — no contiene ninguna mención a materias específicamente religiosas entre las competencias reservadas al legislador central. Únicamente se puede considerar aplicable, en cuanto función exclusiva del Estado, la competencia señalada en el artículo 149.1.1, sobre regulación de las «condiciones básicas» que garanticen la igualdad en el ejercicio de los derechos constitucionales. Esta cláusula debe interpretarse además, de acuerdo con la reserva de ley orgánica (art. 81), así como también en combinación con la reserva de ley general prevista en el artículo 53-1. ${ }^{\circ}$ para el conjunto de los derechos enunciados en el Capítulo Segundo del Título Primero de la $\mathrm{CE}^{3}$. Ese silencio constitucional en materia competencial religiosa se extiende al catálogo de atribuciones (art. 148) cuya asunción por las CC.AA. está directamente autorizada por la Constitución; tampoco aquí se hace referencia alguna en ningún momento a aspectos que pudieran tener una relación directa con el fenómeno religioso.

De este modo, la Ley Orgánica se erige en el único instrumento normativo de carácter general con el que se garantiza un cierto grado de homogeneidad territorial sobre cuestiones y materias «fundamentales» relativas al ejercicio de la libertad religiosa. No obstante, y a raíz de una interpretación siempre

2 Para un detallado examen sobre los títulos competenciales del Estado y las Comunidades Autónomas que entrarían en juego en la tarea de delimitar el posible reparto de responsabilidades — legislativas y administrativas - sobre desarrollo del artículo 16 de la CE, vid. Catalina PONSESTEL TUGORES, Derecho Autonómico y religión. El caso balear. Civitas. 2010.

Junto a la mencionada, algunas otras competencias exclusivas del Estado central pueden incidir en una posible normativa autonómica en este campo, sin duda habría que mencionar la competencia para la celebración de tratados internacionales, y otras de relieve «interno» como el control de la personalidad jurídica de las entidades religiosas, esta última otorgada directamente por la Ley Orgánica de Libertad religiosa (1980). Sin embargo, en contra de lo que parecen sostener otros autores (Pons-Estel, cit.) creemos que no sería imposible, desde un punto de vista constitucional, la firma de acuerdos por parte de las CC.AA. con aquellas confesiones que tengan arraigo social en su territorio, a diferencia del planteamiento estrictamente «estatalista» que se ha seguido hasta ahora en este aspecto de las relaciones entre confesiones religiosas y poderes públicos. 
restrictiva del alcance material de la reserva de ley orgánica mantenida por el Tribunal Constitucional (TC) ${ }^{4}$, se puede colegir que esta regulación no puede ser exhaustiva ni «excluyente» de ámbitos materiales sobre los que pueden incidir la normativa y actuación realizada por entidades subestatales (CC.AA., entes locales).

La ausencia en la CE de una regla específica de atribución de competencias a favor del Estado (art. 149) obliga a utilizar otra pauta de potencial asignación de responsabilidades públicas autonómicas. En efecto, el artículo 149.3 (CE) contempla la aplicación de una regla subsidiaria frente a la inexistencia de una competencia estatal, exclusiva y expresamente indicada en ese mismo precepto: la posibilidad de atribución a las CC.AA. de cualquier competencia que no haya sido atribuida por la Constitución al Estado. La condición que debe cumplirse inexorablemente en este supuesto es que esa competencia tenga un reflejo específico en el Estatuto de Autonomía. En caso contrario no queda vetada constitucionalmente la posible regulación normativa regional, si bien la eventual superposición de las normativas estatal y autonómica sobre la misma materia conlleva la prevalencia en todo caso de la primera sobre la segundas.

En todo caso, es obvio que el artículo 148 de la CE no puede proporcionar ninguna cobertura constitucional a una posible competencia autonómica en materia religiosa, ya que ésta no forma parte del catálogo de potenciales atribuciones autonómicas regulado en su número primero. La función del artículo 148 es únicamente reconocer unas esferas materiales mínimas o fundamentales sobre las que puede incidir el ordenamiento autonómico, respetando las

4 En una de las últimas y más destacadas resoluciones de la jurisprudencia constitucional va a quedar de manifiesto la legitimidad del Alto Tribunal para fiscalizar cualquier decisión administrativa que pueda afectar al ejercicio del derecho fundamental, incluso - como era el caso objeto de esta sentencia (STC 51/2011, de 14 de abril)_ cuando se trate de cuestiones de naturaleza estrictamente religiosa o confesional, como era la supervisión de la idoneidad en la contratación de profesores de religión dentro de centros educativos públicos.

5 Entre los estudios que analizan la proyección de la libertad religiosa sobre un modelo territorial como el italiano, análogo en muchos aspectos al español se puede citar a Angelo LICASTRO, «Libertà religiosa e competenze amministrative decentrate», en Stato, Chiese e Pluralisme confessionale, Rivista telemática (www.statoechiese.it), noviembre, 2010. En este trabajo, se demuestra que la denominada «lógica federal» ha experimentado fuertes resistencias en este ámbito durante la implantación y desarrollo del estado regional italiano, pese a la existencia contrastada de intereses religiosos de carácter territorial. El punto de inflexión, a la vez que elemento de diferenciación con el modelo autonómico español, sería al atribución expresa al Estado central de una competencia sobre relaciones de la República con las confesiones religiosas (art. 117), que no ha sido eliminada ni ha sufrido una variación sustancial con las últimas reformas constitucionales del sistema competencial (año 2001). 
competencias que con carácter exclusivo atribuye la norma fundamental al Estado, las cuales se proyectan en buena medida también sobre esos mismos ámbitos materiales. Pero la ausencia de reglas competenciales específicas no tendría por qué ser interpretado como una implícita prohibición para que las CC.AA., bien a través de sus respectivos Estatutos, bien mediante con la legislación propia, esté capacitadas para abordar algunos aspectos de relevancia en materia religiosa. Entre los contenidos y funciones enunciados en el artículo 148 , y los reservados a la competencia estatal por el artículo 149, quedan espacios regulativos y funciones que una Comunidad Autónoma podría asumir estatutariamente, y ejercer en su caso a través de legislación y reglamentación propia.

El artículo 16.3 de la CE encomienda a los poderes públicos, en forma de mandato u obligación, la cooperación con el conjunto de confesiones religiosas, y en particular con la Iglesia católica. Una primera aproximación al contenido de este precepto constitucional conduce necesariamente a la conclusión de que ese deber de cooperación no tiene por qué tener siempre el mismo contenido político y legislativo ${ }^{6}$, ni tampoco - a nuestro juicio- circunscribirse en exclusiva a las autoridades del Estado central. La expresión «poderes públicos» se emplea siempre en la norma fundamental con la intención de englobar a la totalidad de entidades de derecho público pertenecientes a cualquier Administración institucional o territorial.

Pero esta fórmula genérica conlleva un segundo efecto indirecto, esta vez de carácter competencial. La expresión «poderes públicos», aunque no puede ser considerada una norma atributiva de competencias específicamente, ni puede servir por sí misma para delimitar las funciones de ninguna Administración pública, sin embargo implícitamente manifiesta una opción constitucional, cuya interpretación debe llevarse a cabo de forma sistemática, es decir, en combinación con el silencio que caracteriza al artículo 149, en cuanto a la no adjudicación a favor del Estado de una teórica competencia — exclusiva o compartida- en materia religiosa. Desde esta perspectiva pues, y de acuerdo con el enunciado formal del artículo 16 de la $\mathrm{CE}$, no debe existir un obstáculo constitucional insalvable para que las CC.AA. puedan legítimamente asumir una cuota propia y singular de responsabilidad en el desarrollo de instrumentos institucionales y ámbitos materiales de colaboración con las confesiones y comunidades religiosas arraigadas en su territorio. No obstante, el alcance de esa colaboración «autonó-

6 Vid. Fernando REY, «La decisión del constituyente en materia de conciencia y religión», en La libertad religiosa en el estado social (A.Barrero Ortega y M. Terol Becerra, coords.), Valencia, 2009, pp. 105-116. 
mica» tiene que medirse forzosamente sobre la base de los espacios competenciales que ha dejado abiertos a otros poderes públicos «no estatales» la Ley de Libertad Religiosa (LOLR 7/1980), así como las normas legislativas - y convencionales en su caso- que la desarrollen. Esta premisa interpretativa autoriza a proponer una primera conclusión: las CC.AA. no tienen cerrada en absoluto la posibilidad de desplegar su propio ordenamiento sobre ámbitos importantes conectados con la libertad religiosa.

Por otro lado, algunos principios constitucionales, expresa o implícitamente formulados en la norma fundamental, suministran una fundamentación importante a una eventual «descentralización» en materia religiosa. Por lo pronto, los principios de subsidiariedad y proximidad justificarían, junto con el concepto de «interés autonómico», la adaptación de la noción legal de «notorio arraigo» a una dimensión territorial regional. No existen vetos constitucionales a una «lectura autonómica» de esa previsión contenida en la Ley Orgánica de Libertad Religiosa (art. 7, LOLR, 1980), en virtud de la cual el Estado establecerá acuerdos o convenios de cooperación con las iglesias, confesiones y comunidades religiosas que tengan una implantación social significativa ${ }^{7}$. La norma legislativa no puede ser interpretada en términos competenciales, sino como expresión del cumplimiento de un mandato-finalista enunciado en la norma fundamental (art. 16, CE), el cual por otra parte se dirige al conjunto de poderes públicos sin exclusión.

\section{LA REGULACIÓN DEL «HECHO RELIGIOSO» EN LOS ESTATUTOS DE AUTONOMÍA}

La generalidad de los Estatutos de Autonomía, tanto los originarios como los reformados, no han previsto en sus respectivos articulados normas de compromiso ni competencias específicas que afecten de forma directa a los derechos fundamentales asociados al ejercicio de la libertad religiosa. Sin embargo, existe un modelo estatutario que rompe esta regla casi general. Se localiza en el Estatuto de Autonomía de Cataluña del 2006 (EAC), donde se ha introducido una competencia autonómica, legislativa y ejecutiva que prevé un sistema de relaciones específico entre esa Comunidad y las confesiones religiosas que lleven su actividad en su territorio (art. 161, EAC); y junto a la anterior, se añade además la obligación estatutaria —en cuanto principio rector de sus

Vid. Agustín MOTILLA, «La Ley Orgánica de Libertad Religiosa y las Comunidades Autónomas: la regulación autonómica de la libertad religiosa», en Anuario de Derecho Eclesiástico del Estado, vol. XXVI, 2010, pp. 59 y ss. 
políticas públicas - de promover la convivencia cultural y religiosa y el respeto de la diversidad de convicciones religiosas y filosóficas (art 42). La Generalidad dispone de este modo de un campo de actuación que no se limita a la ejecución de acuerdos adoptados por el Estado con las comunidades e iglesias inscritas en el Registro de Entidades Religiosas, sino que permite en teoría diseñar instrumentos y políticas propias y diferentes a las que se hayan acordado con los poderes públicos estatales. Esa colaboración se proyecta además en el plano «vertical» de las relaciones de la Comunidad Autónoma con estos últimos, participando en la gestión del Registro antes mencionado o ejecutando los acuerdos que el Estado haya alcanzado con carácter general con las diversas confesiones religiosas. En todo caso, el ejercicio de esos títulos competenciales «ejecutivos» en materia de libertad religiosa sólo se puede proyectar sobre esferas materiales sobre las cuales disponga la Generalidad de alguna competencia estatutaria, y siempre de acuerdo con lo que dispongan las leyes estatales ${ }^{8}$.

En el caso de la Comunidad Autónoma de Andalucía, el Estatuto reformado del año 2007 no modifica sustancialmente el panorama general del conjunto de normas estatutarias de la «primera generación». Aparte de sancionar el mandato constitucional del principio de igualdad y la consiguiente prohibición de discriminación —entre otras razones - por motivos religiosos, y la reiteración

8 El artículo 161 contiene una relación bastante concreta de posibilidades de intervención autonómica en el plano de la cooperación de la Generalidad con las diferentes confesiones religiosas arraigadas en Cataluña:

«1. Corresponde a la Generalitat la competencia exclusiva en materia de entidades religiosas que lleven a cabo su actividad en Cataluña, que incluye, en todo caso, la regulación y el establecimiento de mecanismos de colaboración y cooperación para el ejercicio de sus actividades en el ámbito de las competencias de la Generalitat.

2. Corresponde a la Generalitat la competencia ejecutiva en materia relativa a la libertad religiosa. Esta competencia incluye en todo caso:

a) Participar en la gestión del Registro estatal de Entidades Religiosas con relación a las iglesias, las confesiones y las comunidades religiosas que lleven a cabo su actividad en Cataluña, en los términos que determinen las leyes.

b) El establecimiento de acuerdos y convenios de cooperación con las iglesias, las confesiones y las comunidades religiosas inscritas en el Registro estatal de Entidades Religiosas en el ámbito de competencias de la Generalitat.

c) La promoción, el desarrollo y la ejecución en el ámbito de las competencias de la Generalitat de los acuerdos y de los convenios firmados entre el Estado y las iglesias, confesiones y comunidades religiosas inscritas en el Registro estatal de Entidades Religiosas.

3. La Generalitat colabora en los órganos de ámbito estatal que tienen atribuidas funciones en materia de entidades religiosas.» 
del derecho de los padres a que sus hijos reciban una formación religiosa de acuerdo con sus convicciones, la cuestión religiosa queda reducida a un genérico - y ambiguo en cuanto a su verdadero alcance — principio rector de las políticas públicas donde se señala una cierta orientación a la intervención de los poderes públicos autonómicos 9 .

Esta tónica se repite en las normas fundacionales de las demás CC.AA. ${ }^{10}$. No se regula pues en ellas una competencia expresa que permita deslindar de forma concreta un campo de actuación que cuente con una cobertura estatutaria mínima en el tema religioso, salvo la general prohibición de discriminación que ya contempla la CE y los propios Estatutos, pero sin una proyección específica en la esfera competencial autonómica.

Pero la ausencia — como hemos podido comprobar- en la esfera estatutaria de atribuciones o funciones directamente relacionadas con alguna de las dimensiones de la libertad religiosa no tiene por qué imposibilitar la existencia en el sistema general de competencias constitucionales y estatutarias de materias competenciales autonómicas «conexas» con el hecho religioso o que se proyecten directa y expresamente sobre las relaciones con las confesiones religiosas que operan en el territorio de una Comunidad Autónoma. La razón de lo anterior estriba en el conjunto de competencias que el Estatuto atribuye a los poderes públicos autonómicos, e indirectamente también locales (carácter «bifronte» del régimen local), sobre materias que podríamos denominar «conexas» con el hecho religioso. El elenco de estas materias es suficientemente amplio como para deducir del mismo un nivel elevado de implicación autonómica en cuestiones que pueden tener un perfil de naturaleza religiosa: sanidad, asistencia social, educación, medios de comunicación, urbanismo, medio ambiente, patrimonio histórico y cultural. De este modo, la amplia relación de potestades normativas de que dispondrían las CC.AA. sobre esos ámbitos proporciona un campo de actuación normativa lo bastante amplio como para conformar un —implícito pero efectivo- derecho eclesiástico autonómico.

9 El artículo 37.23 del Estatuto del 2007 establece como indirizzo politico teóricamente vinculante, «La convivencia social, cultural y religiosa de todas las personas en Andalucía y el respeto a la diversidad cultural, de creencias y convicciones, fomentando las relaciones interculturales con pleno respeto a los valores y principios constitucionales».

10 No se puede considerar una verdadera excepción lo establecido en el nuevo Estatuto de Aragón, aprobado por LO 5/2007, el cual aborda un objetivo concreto que indirectamente afectaría a la dimensión colectiva de la libertad religiosa, cuando configura en su artículo 23.2) la obligación de la Comunidad de integrar a unas minorías étnicas que, aunque no se diga expresamente en el precepto, están dotadas de unos particularismos culturales y religiosos. 
Por otro lado, este ordenamiento autonómico religioso tiene que respetar en todo caso el mandato constitucional del artículo art. 14, lo que implica la necesaria prohibición, en el ejercicio y actuación de las competencias autonómicas, de cualquier forma o expresión de discriminación basada en motivos religiosos. Por otra parte, la estatutorización del principio de igualdad —a través de fórmulas diversas pero explícitamente recogidas en el articulado— tiene como destinatarios no sólo los sujetos individuales sino también las comunidades religiosas que tienen arraigo dentro del territorio de la Comunidad. Por tanto, esta doble dimensión - constitucional y estatutaria - de la igualdad actuaría como un límite que impediría al conjunto de poderes públicos autonómicos (incluidos los entes locales de la Comunidad) aprobar regulaciones normativas o adoptar decisiones político-administrativas que generasen posibles tratamientos desiguales infundados e injustificados por motivos religiosos, o bien otorgaran un trato privilegiado a alguna confesión religiosa. Ciertamente los poderes públicos autonómicos se encuentran legitimados para «tomar en consideración» las creencias — mayoritaria o minoritarias- a partir fundamentalmente del criterio de su proyección social; sin embargo no lo están para establecer tratamientos o imponer soluciones diferentes a los problemas que puedan incidir en el núcleo esencial del derecho fundamental — tanto en su dimensión externa como colectiva - de la libertad religiosa, cuya tutela y garantía no tiene por qué depender de criterios poblacionales o cuantitativos. La propia evolución experimentada en la sociedad española en general en las últimas décadas hacia una mayor diversidad o pluralismo religiosos —en definitiva, el mismo hecho sociológico que influyó en la labor del constituyente- debe inclinar ahora la interpretación de los mandatos constitucional y estatutarios hacia políticas legislativas que promuevan una mayor una igualdad jurídica, desde la cual no puedan justificarse después aplicaciones reglamentarias o decisiones administrativas que impongan discriminaciones, veladas o solapadas en los preceptos legales, sobre las confesiones y comunidades religiosas minoritarias ${ }^{11}$.

11 Sin embargo, como pone de relieve Eduardo RUIZ VIEYTEZ, ni la Constitución española ni la Legislación en materia religiosa en nuestro país parecen reconocer el valor positivo del principio del pluralismo religioso. Este recelo quizás sirva para explicar todavía la ausencia de normas — estatales y autonómicas — adaptadas a esa nueva realidad social, dado que — como subraya este autor- estas leyes no garantizan de por sí una cobertura completa para el ejercicio de la libertad religiosa de las personas potencialmente beneficiadas, principalmente por la falta de concreción o desarrollo de varias disposiciones. Vid. «La diversidad religiosa en el País Vasco: carencias y propuestas sobre su tratamiento jurídico e institucional», en La diversidad religiosa en el País Vasco: nuevos retos sociales y culturales para las políticas públicas (E. Ruiz Vieytez, coord.),Universidad de Duesto, 2011, pp. 103 y ss. 
No obstante, también la acepción material de la igualdad se erige en un compromiso de los poderes públicos autonómicos. El artículo 9-2 $2^{\circ}$ de la $\mathrm{CE}$ impone al conjunto de poderes públicos la obligación de promover las condiciones necesarias para garantizar la igualdad y libertad reales y efectivas, mediante la desaparición de aquellos obstáculos que impiden ese objetivo y, al mismo tiempo, facilitando la participación de los individuos y los grupos en la vida política, económica, social y cultural. Esta cláusula constitucional contiene de modo implícito una serie de prescripciones en materia religiosa para todos los «poderes públicos»; esta última expresión, por su generalidad permite desplegar su eficacia sobre todas y cada una de las Administraciones públicas cuyas decisiones puedan afectar al ejercicio «igualitario» de la libertad religiosa.

La expresión estatutaria de esos mandamientos constitucionales se mimetiza en los Estatutos de las Comunidades Autónomas, con intensidad y alcance muy similares, si no idénticos, al precepto constitucional. Se van a reconocer allí las obligaciones de los poderes públicos autonómicos para, en el espacio competencial marcado en cada caso, velar y garantizar por «el adecuado ejercicio de los derechos y deberes fundamentales de los ciudadanos», lo que se traducirá a continuación en el deber de adoptar «aquellas medidas dirigidas a promover las condiciones y a remover los obstáculos para que la libertad y la igualdad del individuo y de los grupos en que se integra sean efectivas y reales».

La materialización de la igualdad y libertad — reales y efectivas - en la esfera religiosa únicamente se alcanza a través de la práctica y garantía de lo que el TC ha denominado como «laicidad positiva», que incumbe con la misma intensidad a todos los poderes públicos (estatales, autonómicos, locales) ${ }^{12}$. En cumplimiento por consiguiente de ese mandamiento constitucional las Comunidades Autónomas debe aplicarse en la consecución de un doble objetivo. De un lado, tienen que llevar a cabo una actuación positiva, y prestacional si fuese necesario ${ }^{13}$, para asegurar que el ejercicio del derecho fundamental del artículo

12 El concepto de «laicidad positiva» —o laicidad cooperativa — es interpretado por María J. ROCA, en un triple sentido: la libertad del Estado respecto de las iglesias, la libertad de las iglesias y confesiones respecto del Estado, y finalmente la libertad del individuo y la sociedad respecto de las iglesias y del Estado en cuestiones religiosas. Vid. María J. ROCA, «Laicidad del Estado y garantías en el ejercicio de la libertad: dos caras de la misma moneda», en "El Cronista del Estado Social y Democrático de Derecho», N. ${ }^{\circ}$ 3, 2009, pp. 7-8.

13 La dimensión prestacional — no sólo normativa- de la libertad religiosa ha sido confirmada por la jurisprudencia constitucional en varias ocasiones, entre las cuales se puede mencionar la STC 46/2001, relativa a la función positiva e instrumental del Registro de Entidades Religiosas, como medio de promoción indirectamente para asegurar el ejercicio, igualitario además, del derecho fundamental. Vid. Antonio LÓPEZ CASTILLO, La libertad religiosa en la jurisprudencia del Tribunal Constitucional. Madrid. 2002. 
16 queda garantizado en las mismas condiciones a los sujetos y comunidades religiosas, «tomando en consideración» en un sentido positivo, y no sólo abstencionista, la diversidad religiosa que existe dentro de la Comunidad. De este modo, la intervención de las autoridades autonómicas en los planos legislativo y administrativo cobra así un carácter prescriptivo —y no sólo como mera facultad discrecional- en aquellas esferas competenciales que puedan afectar al ejercicio individual o colectivo del derecho fundamental.

Por otra parte, esa actuación autonómica en la esfera religiosa tendría que ofrecer un tratamiento legal y reglamentario imprescindible para asegurar que no se produzcan fenómenos de discriminación, tanto explícita como indirectamente, por razones de pertenencia a comunidades religiosas minoritarias dentro del territorio de cada Comunidad Autónoma. La consecución de este objetivo puede implicar la previsión legislativa de una serie de dotaciones prestacionales por parte de la Administración autonómica —o local—, mediantes las cuales se materialice la igualdad en el acceso a determinados bienes y servicios que permiten un efectivo y pleno ejercicio de la libertad religiosa: asistencia religiosa diferencial en las escuelas y establecimientos públicos dependientes de la Administración vasca (hospitales, tanatorios) o estatal (centros penitenciarios), acceso a medios de comunicación pública, asistencia social a través de entidades religiosas.

Sin embargo, el único modelo estatutario que ha incluido una competencia autonómica, legislativa y ejecutiva, en las relaciones de la Comunidad con las confesiones religiosas que lleven su actividad en su territorio está contenido en el Estatuto catalán aprobado en el 2006 (art. 161, EAC), donde además se ha configurado una obligación estatutaria de la Comunidad - como principio rector de sus políticas públicas - de promover la convivencia cultural y religiosa y el respeto de la diversidad de convicciones religiosas y filosóficas (art 42).

Aquí tendría una notoria importancia para lograr ese resultado el establecimiento de una normativa propia que prevea la disposición de espacios públicos por parte de las diferentes comunidades religiosas con arraigo social en la Comunidad, mediante la imposición de reglas de planeamiento urbanístico que, en primer lugar, establezcan reservas destinadas a la apertura de centros de cultos, en los cuales se ejercita la dimensión colectiva externa del derecho fundamental; y en segundo término también, que aseguren una distribución de esos espacios o reservas urbanísticas sobre la base de criterios de equidad y proporcionalidad entre las diferentes confesiones o comunidades religiosas arraigadas en ese medio social. 


\section{LA LEY ORGÁNICA SOBRE LIBERTAD RELIGIOSA COMO MARCO NORMATIVO OBLIGATORIO DE REFERENCIA PARA LAS COMUNIDADES AUTÓNOMAS}

\subsection{Contenido orgánico del derecho fundamental y posibles márgenes de intervención autonómica}

Aun cuando la CE no atribuye expresamente al Estado una competencia exclusiva sobre colaboración con las confesiones religiosas, sin embargo esto no ha impedido que se haya aprobado por aquél la normativa esencial que regula esta materia, en virtud de la potestad que le confiere la norma fundamental para aprobar mediante Ley Orgánica la regulación esencial de los derechos fundamentales y libertades públicas (art. 81, CE). Así pues, a las leyes y tratados que contienen los compromisos y obligaciones fundamentales del Estado en sus relaciones con estas confesiones, hay que añadir otro parámetro legislativo — la Ley Orgánica de 5 de julio de 1980 — que se convierte en referencia ineludible y necesaria para cualquier desarrollo normativo que pretenda llevarse a cabo por la Comunidad Autónoma sobre materias que afectan a las relaciones de cooperación con comunidades religiosas. Pero aunque la libertad religiosa se configure como un derecho fundamental, y por tanto la determinación de su régimen jurídico haya quedado reservada a la competencia del legislador orgánico (art. 81, CE), existen suficientes argumentos para considerar que las CC.AA. disponen de un cierto espacio regulativo propio, que podría suponer incluso la posibilidad de fijar estándares normativos en aspectos significativos del derecho fundamental.

En este sentido, hay que recordar en primer término que el TC ha venido manteniendo de forma constante una interpretación restrictiva del objeto material de la reserva de ley orgánica sobre «derechos fundamentales y libertades públicas» (art. 81, CE). A partir de esta doctrina jurisprudencial cabría deducir que no todo lo relativo, o que pueda afectar directamente al ejercicio de esta categoría específica de derechos constitucionales, quede siempre y en todo caso fuera del alcance de la potestad legislativa de las CC.AA. Únicamente sería necesario regular mediante esta categoría «excepcional» de fuente normativa el régimen general o, de otro modo, el núcleo básico de cada uno de los derechos fundamentales y libertades públicas. Desde esta posición interpretativa no quedaría en consecuencia excluida la posibilidad de reconocer ámbitos materiales dentro del derecho fundamental a la libertad religiosa susceptibles de una eventual legislación autonómica. 
Por otro lado, no resultaría aceptable compensar esa concepción restrictiva de la reserva material de Ley Orgánica a través de una interpretación extensiva y desproporcionada de la competencia «transversal» que otorga la CE al Estado para regular las «condiciones básicas» en el ejercicio de los derechos constitucionales (art. 149.1.1). Se trata de una cláusula con una evidente potencialidad para restringir los márgenes competenciales de las CC.AA. para aprobar una normativa propia y con cierto grado de diferencialidad sobre aspectos importantes del régimen jurídico de los derechos fundamentales. En esta misma línea, el TC ha puesto objeciones al intento por el Estado central de utilizar esta regla de atribución funcional como método indirecto de privación o desposesión competencial de las entidades subestatales; la traducción que realiza la jurisprudencia constitucional de esta noción como las «posiciones jurídicas fundamentales» ofrecería - a nuestro juicio — una apertura constitucional para que los legisladores autonómicos aborden la regulación de determinadas dimensiones de la libertad religiosa dentro su ámbito territorial. Los elementos de diferenciación que introduzca esa normativa no tienen necesariamente que colisionar con la esfera competencial que corresponde al Estado en virtud del artículo 149.1.1 de la $\mathrm{CE}$, ya que la igualdad «básica» en el ejercicio de los derechos constitucionales no se identifica con la imposición de una total uniformidad jurídica.

Así pues, la realización de un diagnóstico específico del contenido de la Ley Orgánica de Libertad Religiosa (1980) no constituye un límite infranqueable a la intervención y regulación de las CC.AA., incluso en el supuesto - casi generalizado, como hemos podido observar- de no disponer de una competencia específica en materia religiosa. Ahora bien, la premisa anterior debe complementarse con los matices necesarios, ya que un examen del contenido de la LOLR permitiría distinguir entre prescripciones o normas que tienen una vocación claramente homogenizadora, en la medida en que tocan aspectos «esenciales» del régimen jurídico de la libertad religiosa, de otros preceptos de la Ley que justificarían desarrollos normativos «no orgánicos» del derecho, implantados por otras normas estatales o bien procedentes de las CC.AA. Aunque no es posible localizar en el texto de la LOLR una declaración explícita de la que se deduzca nítidamente la anterior diferenciación, existe un amplio consenso doctrinal sobre la condición estrictamente «orgánica» —únicamente- de los artículos 1 a 4 de la norma. Fuera de los ámbitos materiales contenidos en esos preceptos, no sería legítimo negar la posibilidad de un desarrollo e innovación normativos de las CC.AA., en virtud de las competencias estatutarias con que cuentan en materias como educación, urbanismo o sanidad.

Entre las cláusulas normativas de la Ley Orgánica que configuran aquel régimen jurídico orgánico y esencial del derecho fundamental hay que anotar concreta- 
mente dos, con las cuales queda trazada la frontera que en ningún caso podrían superar los poderes públicos autonómicos. En primer lugar, la definición que lleva a cabo su artículo 2 del contenido de la libertad religiosa y de culto, como «el derecho de las Iglesias, Confesiones y comunidades religiosas a establecer lugares de culto o de reunión con fines religiosos, a designar y formar a sus ministros, a divulgar y propagar su propio credo, y a mantener relaciones con sus propias organizaciones o con otras confesiones religiosas, sea en territorio nacional o en el extranjero». La segunda referencia legislativa con carácter prescriptivo para el conjunto de los poderes públicos viene contenida en su artículo 3.1, en el cual se van a señalar los límites a los derechos «internos» que delimitan el alcance de la libertad religiosa: «la protección del derecho de los demás al ejercicio de sus libertades públicas y derechos fundamentales, así como la salvaguardia de la seguridad, de la salud y de la moralidad pública, elementos constitutivos del orden público protegido por la Ley en el ámbito de una sociedad democrática».

Pero las anteriores cláusulas legislativas son lo suficientemente ambiguas en cuanto a la señalización de un concreto contenido normativo, que resulta difícil imponer a través de ellas unos indicadores o directrices muy definidas sobre las condiciones y alcance en las que se puede ejercer el derecho fundamental. Concretamente respecto a la libertad de culto se consagra como un derecho fundamental, cuyo contenido esencial — la libertad para establecer lugares de cultono admite injerencias de los poderes públicos. Sin embargo, ese ámbito de inmunidad o de autonomía no sería absoluto cuando entran en juego otros valores, principios o derechos con los que ha de armonizarse el derecho fundamental. Estos parámetros de modulación, enunciados de forma explícita en el texto de la Ley, justificarían por sí mimos la potestad de los poderes públicos para articular un procedimiento administrativo que ordene el sistema de apertura un funcionamiento de los centros y lugares de culto de cualquier confesión o comunidad religiosa. De este modo, y como elementos constitutivos de la noción «orden público» —único límite potencial previsto constitucionalmente a la libertad religiosa - la seguridad, la salud e inclusive la moralidad pública van a representar los elementos de referencia que cualquier legislador autonómico debe utilizar para delimitar el significado de las dimensiones colectiva y externa de la libertad religiosa ${ }^{14}$. De más dudosa legitimidad constitucional sería

14 Sin duda también, las autoridades autonómicas y municipales van a estar constreñidas por los mandamientos normativos contenidos en una legislación de extranjería aplicable directamente a situaciones de eventual conflicto generadas el fenómeno de la inmigración. En la Ley Orgánica 8/2000 (texto reformado de la LO 4/2000) sobre derechos y libertades de los extranjeros en España, no caben actitudes ni conductas contrarias al derecho fundamental a la libertad religiosa, entrando en un supuesto de infracción muy grave cualquier discriminación o restricción 
la posibilidad de añadir algún otro límite no comprendido en el catálogo de potenciales restricciones enunciado en la LOLR. En tal caso, se podría estar traspasando una frontera competencial y sustantiva impuesta por la Constitución y la Ley orgánica, de la que se infieren unas potenciales restricciones vinculadas exclusivamente al concepto de orden público y que no cabría ampliar por ningún legislador (estatal o autonómico). No obstante, el alto índice de indeterminación que encierra tanto esa noción constitucional, así como los elementos que la configuran desde el punto de vista legal (seguridad ciudadana, ordenación territorial y urbanismo, medio ambiente, sanidad), siguen otorgando un amplio margen para la interpretación que de ellos puedan hacer los legisladores autonómicos en un hipotético proceso de adaptación a la concreta realidad socio-religiosa de las CC.AA. La «ductilidad» constitucional y legislativa juega entonces a favor de posibles iniciativas legislativas regionales destinadas a crear procedimientos administrativos que regulen la apertura y el funcionamiento de los lugares de culto ubicados en su territorio, siempre que se respeten los mismos límites y restricciones contenidas en la norma estatal.

La libertad religiosa no admite a priori más restricciones que las señaladas por la Ley Orgánica, donde se ha sintetizado el equilibrio entre aquella libertad fundamental y otros derechos de los que son titulares del resto de los ciudadanos. En este sentido, la LOLR ha implantado también una cláusula de apertura —en la misma línea que el Convenio Europeo de Derechos Humanos (artículo 9.2)que justifica hipotéticas restricciones a la libertad de cultos en el que caso de conflicto con otras libertades o derechos fundamentales (la protección del derecho de los demás al ejercicio de sus libertades públicas y derechos fundamentales) (artículo 3) ${ }^{15}$.

sobre aquéllos por motivos de conciencia o religión. El único límite que legitima una limitación en el ejercicio de este derecho sería el comprendido dentro de la noción de orden público, si bien esta condición o excepción no se encuentra expresamente prevista en esas disposiciones legislativas ates mencionadas, pero resulta necesario extraerlas en su caso desde las normas de derecho internacional aplicables a los extranjeros, según lo establecido en el artículo 3.2 de la LO 4/2000. Vid. Jasone ASTOLA MADARIAGA, «Multiculturalidad y Estado de Derecho: la gestión de la diferencia en el sistema constitucional español», en Constitución y democracia: 25 años de Constitución democrática en España: (actas del congreso celebrado en Bilbao los días 19 a 21 de noviembre de 2003 (Miguel Angel García Herrera, coord.), Vol. 1, 2005, pp. 351-372.

15 La aplicación e interpretación de las cláusulas que hacen referencia a la libertad religiosa del Convenio de Roma han recibido una atención abundante e intensa en la doctrina; entre los numerosos estudios que tratan la evolución de la jurisprudencia del Tribunal Europeo de Derechos Humanos podríamos citar los contenidos en La Europa de los Derechos Humanos. El Convenio Europeo de Derechos Humanos (J. García Roca y P. Santolaya, coords.), Centro de Estudios Políticos y Constitucionales, Madrid, 2005; o Gloria Fernández Arribas, «La libertad religiosa en la jurisprudencia del Tribunal Europeo de Derechos Humanos», en La libertad religiosa en el estado social, cit. pp. 443 y ss. 
Por lo tanto, habría que incluir en el catálogo de eventuales restricciones, todas aquellas que se encuentran justificadas por cualquier libertad o derecho de los reconocidos en el Título, si bien únicamente en la Sección Primera, Capítulo Segundo (art. 15 a 29). No obstante, el «margen de apreciación» de estos límites, enunciados en su dimensión legislativa con una formulación todavía bastante ambigua, debe estar siempre sometido a un test de proporcionalidad que justifique de manera suficiente la imposición de limitación en la libertad de cultos.

\subsection{Normas de Derecho Internacional y acuerdos del Estado español con las confesiones religiosas, como parámetros normativos que limitan las competencias autonómicas en materia religiosa y para la apertura de centros de culto}

Debido a su naturaleza «paccional» e internacional, los acuerdos suscritos en 1979 entre el Estado español y la Iglesia Católica delimitan un régimen jurídico en buena medida «blindado» a la posible regulación legislativa de las CC.AA. en materia religiosa. Cualquier desarrollo legislativo y reglamentario (estatal y autonómico) de materias contenidas en esos pactos tiene que respetar rigurosamente los compromisos y acuerdos que se contienen en esas normas de derecho internacional. Es justamente la naturaleza convencional de los acuerdos lo que vendría a modular en un sentido restrictivo las posibles competencias religiosas del legislador autonómico.

En lo que se refiere concretamente a la creación y apertura de centros de culto católicos, el Acuerdo suscrito entre España y el Vaticano sobre Asuntos Jurídicos estipula únicamente el reconocimiento por el Estado español a la Iglesia Católica del «derecho de ejercer su misión apostólica» así como «el libre y público ejercicio de las actividades que le son propias y en especial las de culto, jurisdicción y magisterio» (artículo primero) ${ }^{16}$. De esta vaga mención a determinadas actuaciones con proyección externa o social de la Iglesia Católica no es posible inferir una cláusula atributiva de competencias a favor de la potestad del Estado para establecer en exclusiva una regulación de los lugares destinados al

16 La bibliografía sobre este tema es muy abundante; en relación con la dimensión territorial de estos Acuerdos internacionales podríamos suscribir la opinión de Castro Jover, para la que resulta evidente que el desarrollo estatutario pone de manifiesto que una parte significativa del ejercicio de la libertad religiosa, en su doble dimensión individual y colectiva, se despliega en el ámbito de actuación y regulación de las Comunidades Autónomas, y en concreto de la Generalidad de Cataluña tras la importante reforma estatutaria del año 2006. Vid. Adoración CASTRO JOVER, «Desarrollo y aplicación por la Comunidades Autónomas de los Acuerdos de 1979 entre el Estado español y la Santa Sede», en Anuario de Derecho Eclesiástico del Estado, vol. XXVI, 2010, pp. 461-488. 
culto. Se ha dejado por tanto un amplio margen de discrecionalidad para la concreción posterior, en el plano interno, de las fuentes normativas encargadas de concretar las condiciones en que se va dar cumplimiento a esos compromisos adquiridos en la esfera internacional.

Tampoco tiene por qué implicar un límite a la potencial capacidad autonómica para responsabilizarse de la ejecución de los Acuerdos el expreso reconocimiento que se hace en ellos del carácter «inviolable» de esos lugares de culto (apartado 5, artículo primero). Todo lo contrario, esa inviolabilidad es una noción que queda automática y necesariamente ligada al ejercicio de las competencias sobre urbanismo, materia ésta que entra dentro de la esfera de atribuciones propias de las CC.AA. y que —en un sentido sustantivo— no cabe traducir como la posibilidad de eximir a los lugares de culto de la religión mayoritaria del cumplimiento de las reglas urbanísticas que se aplican e imponen a cualquier edificación o inmueble en virtud de los instrumentos de planeamiento generales. El Acuerdo parece limitar su alcance a la obligación de informar a las autoridades religiosas — quienes deben ser oídas—, y en todo caso al derecho que tienen éstas para eliminar su «carácter sagrado» previamente a la ejecución de una demolición del lugar de culto.

Por otro lado, los acuerdos que alcanzó en 1992 el Estado con otras comunidades religiosas, y dentro de las minoritarias las que cuentan con un mayor arraigo social (islámica, israelita y evangélica), tampoco contienen compromisos ni obligaciones muy concretas para los poderes públicos en materia de lugares de culto ${ }^{17}$. Esta ausencia casi por completo de prescripciones legales sobre condiciones de apertura y funcionamiento de los lugares de culto remite indirectamente al legislador sectorial —estatal o autonómico — la determinación de esos requisitos, otorgando de este modo un margen de autonomía regulativa muy elevado a aquella Administración competente en la esfera urbanística (CC.AA.), lo que implica una capacidad de hecho indiscutible para aprobar normas que afectan a aspectos nucleares de la dimensión externa de la libertad religiosa. Por otro lado, las leyes que se aprobaron seguidamente y que contienen los términos en que se firmaron aquellos acuerdos, van a calificar también de inviolables a los lugares de culto pertenecientes a estas confesiones, así como el derecho a ser oídas antes de proceder a la demolición de uno de ellos; con la excepción aquí de que exista «urgencia o peligro».

17 Vid. David GARCÍA-PARDO, «Desarrollo y aplicación por la Comunidades Autónomas de los Acuerdos de 1992 con las minorías religiosas», en Anuario de Derecho Eclesiástico del Estado, vol. XXVI, 2010, pp. 489-519. 
Dentro del régimen jurídico previsto en las leyes de 1992, se establecen las excepciones de ocupación e imposición de servidumbres, de acuerdo con lo previsto en la Ley de Expropiación Forzosa (art.119). Asimismo, y según el texto de los acuerdos incorporado a cada una de las normas legislativas, los lugares de culto «podrán ser objeto de anotación en el registro de Entidades Religiosas». Se contempla además una exención de carácter tributario, concretamente del Impuesto de Bienes Inmuebles y de las contribuciones especiales, que se proyecta ampliamente sobre cualquier centro de destinado al culto, dependencias administrativas o locales anejos que puedan estar destinados tanto al culto como a la formación religiosa de miembros del clero de esa confesión religiosa.

Pero probablemente lo más destacado de esta legislación estatal sea la delimitación que proporciona del concepto «centro de culto». Al margen de las nomenclaturas tradicionales que se emplean por cada confesión, los tres acuerdos coinciden en señalar como lugares de culto a aquellos «edificios o locales» destinados «de forma exclusiva» a la práctica habitual de la oración, formación o asistencia religiosa. El carácter o naturaleza de centro de culto no se obtiene sólo por el cumplimiento de las finalidades señaladas legalmente, sino que se requiere además una «certificación» específica expedida por las autoridades religiosas de cada confesión.

Entendemos que la definición aportada por esas tres leyes estatales representan algo más que unos simples indicadores orientativos, aplicables a la determinación de lo que sea «centro de culto» para cualquier entidad o Administración pública. Al contrario, contienen unas directrices interpretativas que resultan válidas y en potencia vinculantes para una regulación normativa de carácter urbanístico.

Las exigencias marcadas legalmente son bastante explícitas y no ofrecen demasiada incertidumbre sobre su significado:

a) Condiciones físicas o arquitectónicas: pueden ser edificios $-\mathrm{o}$ inmuebles - independientes, o bien tratarse de «locales»

b) Condiciones funcionales: estar destinados, de manera exclusiva, a una serie de fines de naturaleza religiosa: culto, asistencia o actividades formativas religiosas

c) Condición «eclesiástica»: la necesaria acreditación de centro «oficial» de culto mediante la correspondiente certificado por las autoridades confesionales.

Sin embargo, de las anteriores condiciones impuestas legalmente a cualquier confesión minoritaria, sólo las dos primeras deberían ser tomadas en consideración como elementos definitorios del modelo-tipo (centro de culto) en supuesto de que sean objeto de regulación por las CC.AA. El valor normativo de estos 
parámetros puede ser interpretado en clave de «normativa básica» o «condiciones básicas», de manera que aquéllas dispondrían de un espacio material suficiente para concretarlos en una esfera territorial y competencial propia. De este modo, el desarrollo normativo que lleve a cabo el legislador estatal de la noción «centro de culto» no tiene por qué vaciar de contenido la capacidad legislativa de las Comunidades a la hora de establecer una definición particular sobre ese mismo concepto.

Sin embargo, el principio de aconfesionalidad, y su efecto inmediato como principio de separación Iglesia/Estado, debe conducir a negar la virtualidad de la «certificación» eclesiástica o religiosa en aquellos procedimientos administrativos que se implanten para la concesión de autorizaciones a la apertura de centros de culto. De este modo, la Administración competente no estaría subordinada en ningún caso a la «acreditación confesional», en el momento de imponer aquellas reglas urbanísticas que se exigen para autorizar la puesta en funcionamiento de un centro religioso.

Los acuerdos de 1992 con las religiones minoritarias se inspiran en un principio programático que aparece después vagamente formulado en los textos legislativos y que hace referencia al compromiso del Estado con la «protección de los lugares de culto». Sin embargo, no se mencionan en ningún momento medidas, derechos u obligaciones en las que se concretaría ese objetivo, aunque, en todo caso, se puede deducir aquél de la voluntad del legislador estatal, y en consecuencia se trata de un deber extensible al conjunto de los poderes públicos.

\section{VIABILIDAD CONSTITUCIONAL Y COMPETENCIAL PARA UNA LEGISLACIÓN AUTONÓMICA SOBRE CENTROS DE CULTO}

La libertad religiosa no se puede entender como un derecho fundamental ilimitado. Por esta razón, la ordenación urbanística y la supervisión administrativa para la apertura de centros de culto resulta compatible con el libre ejercicio de la libertad religiosa, en la medida en que ningún derecho fundamental de la CE se ha concebido con carácter absoluto e incondicionado cuando entra en potencial conflicto con otros derechos subjetivos, o bien con un interés general o colectivo respecto del cual exige una operación de ponderación por parte de los poderes públicos (legislador, Administración, órganos jurisdiccionales). La aplicación de esta concepción no absoluta — sería más correcto decir «equilibrada»— de la libertad religiosa en el ámbito urbanístico, y concretamente en relación con la apertura de centros de culto, implica la legitimidad de una regulación autonómica que determine las condiciones necesarias para garantizar 
esa dimensión colectiva y externa del derecho fundamental, incluyendo dentro de esa licitud constitucional la posibilidad de imponer un procedimiento de autorización en forma de licencia de apertura por parte de las autoridades competentes en materia de gestión urbanística (Ayuntamientos).

Pero la normativa que apruebe el legislador autonómico, primero, y la intervención y control de los entes locales, después, no pueden impedir ni poner trabas formales excesivas al ejercicio del culto por las comunidades religiosas. Como hemos venido sosteniendo, la mejor forma de garantizar la plena libertad e igualdad religiosa consiste en una acción positiva de los poderes públicos orientada hacia un doble objetivo. De un lado, el establecimiento de una medida prestacional de carácter jurídico, que adoptaría la fórmula de una reserva obligatoria para equipamientos colectivos de naturaleza religiosa en los instrumentos de planeamiento futuros aprobados por las corporaciones municipales. La adopción en una norma de rango legal de esta obligación pública tendría la virtualidad de configurar indirectamente un «derecho de crédito» de los grupos y confesiones religiosas, en el sentido de activar jurídicamente - $-\mathrm{y}$ desde el punto de vista jurisdiccional también - la garantía del ejercicio de la libertad religiosa en esta faceta de libertad de cultos. De otra parte, la regulación de una serie de condiciones o exigencias de carácter urbanístico para la apertura de centros de culto no tiene por qué significar una limitación desproporcionada e irrazonable de la libertad religiosa, ya que representa el resultado de un ejercicio de ponderación de intereses en presencia que, en materia de derechos constitucionales, la propia jurisprudencia constitucional se ha encargado siempre de imponer como exigencia, y no sólo como efecto de la autonomía del legislador y los demás poderes públicos. Ese mandato a favor de la igualdad real y efectiva que sanciona la CE y los EEAA se vería cumplido en buena medida con el establecimiento de unos parámetros legales que han de ser aplicados inexorablemente por los ayuntamientos, como poderes públicos competentes de la gestión urbanística, evitando así actuaciones y decisiones tras las cuales se solapan visiones todavía discriminatorias de las minorías religiosas.

Partiendo de la premisa de que el modelo urbanístico es competencia del legislador autonómico, así como el diseño de las técnicas o instrumentos de planeamiento que se empleen en su aplicación (STC 61/1997), el «impacto» que pueda tener sobre el ejercicio de un derecho fundamental como la libertad religiosa no tiene por qué conducir necesariamente a una intromisión ilegítima del poder legislativo autonómico sobre el campo material reservado al legislador estatal. Este último no sólo viene delimitado por la regulación de aspectos «esenciales» y «básicos» (art.81, art.149.1.1) que afectan al ejercicio de derechos fundamentales y libertades públicas. En conclusión, la armonización entre los 
títulos competenciales de que dispondría el Estado (en especial, el enunciado dentro del artículo 149.1.1) y aquellos que los Estatutos otorgan a las CC.AA. —urbanismo, medio ambiente, orden público, sanidad interior- resulta viable reconocer, desde una perspectiva constitucional, un espacio regulativo autonómico para regular las condiciones de apertura de los centros de culto.

Por otra parte, la Ley de Suelo del Estado (Ley 8/2007) tampoco ha establecido reglas concretas de aplicación a la ordenación y apertura de lugares de culto en la determinación de los principios y criterios que se deben aplicar al diseño de la planificación urbanística. No obstante, algunos de esos principios tienen un especial relieve e importancia en la adaptación autonómica de las normas urbanísticas estatales a los procedimientos administrativos que en su caso se establezcan para regular la creación y el uso de equipamientos de naturaleza religiosa.

En primer lugar, la Ley 8/2007 reconoce el derecho a la igualdad como mandamiento que obliga a todos los poderes públicos a promover un «resultado equilibrado» en la ordenación territorial y urbanística. Obviamente ese concepto incluye un tratamiento específico de los centros culto orientado a la cohesión social entre comunidades religiosas asentadas en la comunidad. Asimismo hay que resaltar otra directriz legislativa, relativa al derecho a acceder en condiciones de igualdad ( «no discriminatorias y de accesibilidad universal») a la utilización de dotaciones públicas y equipamientos colectivos, que tiene sin duda una evidente traslación al proceso de asignación de reservas de suelo dedicados a esta finalidad. En definitiva, el legislador estatal está imponiendo, directa o indirectamente, unos parámetros urbanísticos que deben ser utilizados tanto por las leyes autonómicas sectoriales aprobadas específicamente sobre urbanismo - $\mathrm{o}$ de incidencia en esta materia - como por las Administraciones competentes en la elaboración de los instrumentos de planeamiento urbano (entes locales) ${ }^{18}$. No obstante, la generalidad de esos objetivos marcados en la ley del Estado no suponen - a nuestro juicio - una restricción especialmente intensa, desde la cual quede estrechamente condicionada la autonomía legislativa de la Comunidad a la hora de aprobar una ley —o normas legislativas dentro de la ley general sobre urbanismo - que regule la apertura de lugares de culto.

Pero por lo general no es posible localizar en la legislación urbanística autonómica unas reglas suficientemente concretas y específicas que diseñen un modelo propio y diferenciado para la apertura centros confesionales. Sí se recogen al

18 Sobre este particular, vid. Marcos GONZÁLEZ SÁNCHEZ, «Competencias de las entidades locales en relación con los lugares de culto», en Anuario de Derecho Eclesiástico del Estado, vol. XXVI, 2010, pp. 4559 y ss. 
menos unas previsiones o directrices — vinculantes en efecto para la Administración local encargada del planeamiento urbanístico - relativas a un sistema de reservas sobre equipamientos colectivos privados, tales como centros de carácter comercial, religioso; o bien igualmente la determinación dentro de aquellos elementos necesarios de la red dotacional de los sistemas locales, de unos «equipamientos privados dedicados a uso religioso».

Desde este tipo de previsiones legislativas de esta naturaleza, las corporaciones municipales se encuentran legitimadas para adoptar normas reglamentarias (ordenanzas y reglamentos) —o instrumentos concretos en su planificación urbana- que dieran respuesta a las necesidades de las diversas confesiones religiosas asentadas en los territorios de las CC.AA.; aunque la generalidad de estas directrices legislativas no garantizaría por sí sola una ordenación sistemática y mínimamente homogénea en esta materia, con la cual sea posible además tutelar con ciertas garantías el derecho fundamental a la libertad de culto en el conjunto de comunidades religiosas. Por lo pronto, esa generalidad en la esfera de la legislación urbanística —estatal y también autonómica - no impide que los ayuntamientos cumplan taxativamente con la obligación de establecer reservas de espacio para estos equipamientos religiosos, como tampoco se fijan en ella con la concreción necesaria las condiciones o estándares objetivos que deberían aplicar las entidades locales a las peticiones de apertura de centros de culto.

Sería perfectamente viable, por otro lado, regular la posible adopción de métodos o técnicas de «buen gobierno» o gobernanza en los procedimientos urbanísticos de ordenación de espacios reservados a centros de culto, dando cumplimiento a un mandato constitucional del artículo 9.2.e, desde el que se insta al conjunto de los poderes públicos a impulsar la participación de los ciudadanos en la vida social y cultural. Como una garantía además de la adopción de criterios de equidad, y para evitar posibles riesgos de discriminación en la adjudicación y aplicación de condiciones de apertura de los centros de culto, sería perfectamente válida —en términos competenciales - la articulación por las CC.AA. de métodos de colaboración de los representantes de las minorías (y mayoría) religiosas en los procedimientos urbanísticos y reglamentarios aplicables a esas decisiones administrativas.

El diseño en la esfera legislativa autonómica de un «espacio institucional» de colaboración interinstitucional (autonómico y municipal), tendría la doble finalidad, primero, de asegurar la coordinación y cooperación entre las Administraciones competentes, al tiempo que sería un mecanismo idóneo en la la búsqueda de consensos y soluciones a los conflictos que puedan llegar a producirse entre instituciones, sociedad y minorías religiosas. 
El problema de la «segregación» de centros pertenecientes a minorías religiosas es uno de los riesgos que puede producir el vacío legislativo. Las condiciones de seguridad deben ser complementadas por condiciones de «dignidad» en la ubicación decidida para la apertura de centros religiosos. Este problema no ha encontrado todavía una respuesta apropiada en la legislación urbanística (estatal y autonómica), lo que está llevando con frecuencia a situaciones de tensión producidas por el rechazo a las decisiones municipales que auspician el aislamiento o la lejanía del núcleo poblacional de centros de culto pertenecientes a comunidades religiosas minoritarias. No existen por ahora sistemas de control en las operaciones de ubicación y asignación espacial de estos lugares de culto, de forma que no se produzcan discriminaciones palpables y se fomente una mayor integración social de esos colectivos. Con frecuencia las dificultades se pueden presentar no tanto frente a actuaciones políticas explícitas —en forma de imposiciones o interpretaciones excesivamente rigurosas de la normativa urbanística-, sino por la pasividad u omisión de los Ayuntamientos en los procedimientos administrativos que se impulsan para la apertura de centros religiosos. A veces incluso el problema se plantea por la utilización de coartadas jurídicas que ocultan un planteamiento institucional discriminatorio (el caso de los minaretes en Suiza es bastante representativo) que ponen de relieve la vigencia de una cultura religiosa que aspira todavía a mantener una hegemónica aunque sea de carácter más simbólico que efectivo.

La viabilidad constitucional de una legislación autonómica sobre lugares de culto tiene que superar una última prueba frente a la necesidad de respetar la garantía institucional de la autonomía local ${ }^{19}$. La aplicación de cualquier medida legislativa en esta materia va a tener lugar siempre en un espacio territorial definido por la competencias municipales que derivan de ese principio constitucional (art. 137, CE). El equilibrio entre autonomía municipal y autonomía subestatal o regional no puede obviar, de otra parte, la obligación que incumbe también a la autoridades locales de ponderar la garantía de aquélla con el respeto a esta dimensión colectiva y externa de la libertad religiosa. Las CC.AA. encuentran así una cobertura constitucional innegable para supervisar los procedimientos administrativos en los que cuales se sustancia la apertura de los centros de culto de las confesiones minoritarias.

19 La relación entre administración local, urbanismo y el multiculturalismo ha sido analizado por Juli PONCE en «Sociedades pluriculturales y administraciones locales: inmigración, diversidad y convivencia en las ciudades. Reflexiones críticas», en Quaderns Dret Local, núm. 11, junio, 2006, pp. 37 y ss. El autor expone en este trabajo un catálogo de problemas, así como de posibles soluciones que plantea la ordenación urbana en materia de centros de culto, como forma de evitar la exclusión social y para cumplimiento efectivo del principio constitucional de Estado social. 


\section{LA APERTURA DE CENTROS DE CULTO COMO UN DERECHO CONSTITUCIONAL DE CONFIGURACIÓN LEGAL SUSCEPTIBLE DE SER REGULADO POR EL LEGISLADOR AUTONÓMICO}

El análisis que se acaba de hacer conduce a la conclusión de que la apertura de centros de culto adopta siempre el formato de un «derecho de configuración legal», una de cuyas principales garantías radica en la reserva de espacios para este tipo de equipamientos comunitarios, de interés general o colectivo, dentro de los instrumentos de planeamiento urbanístico. Además, esa regulación legislativa debería ir acompañada igualmente del establecimiento de unos parámetros (mínimos/máximos) que se implementarían en cada contexto social-urbano, en función del grado de diversidad religiosa. El legislador podría incluir unos criterios mínimos o básicos de distribución de esa reserva para equipamientos religiosos, dando cumplimiento a la obligación contenida en la Ley 8/2007, cuyo artículo 4 reconoce el derecho del ciudadano a acceder «en condiciones no discriminatorias y de accesibilidad universal, a la utilización de las dotaciones públicas y los equipamientos colectivos abiertos al uso público, de acuerdo con la legislación reguladora de la actividad de que se trate».

Ciertamente ese derecho no es incompatible con la restricción, o prohibición inclusive, a la apertura de nuevos lugares de culto en determinadas zonas o áreas urbanas, para garantizar otros derechos o valores constitucionales, como los señalados en el artículo 16 de la CE y el artículo 3 de la LOLR: «el orden público, la protección del derecho de los demás al ejercicio de sus libertades públicas y derechos fundamentales, la salvaguardia de la seguridad, de la salud y de la moralidad pública, elementos constitutivos del orden público protegido por la Ley en el ámbito de una sociedad democrática.» En esta operación de delimitación de contenidos y alcance del derecho fundamental sería imprescindible, además, conciliar el principio de igualdad $\left(14\right.$, y $\left.9-2^{\circ}\right)$ con la necesidad de una ordenación racional del territorio. Este equilibrio puede ofrecer cobertura jurídica a un hipotético derecho subjetivo a exigir que se apruebe un plan urbanístico (o a que se modifique el existente); sin embargo no puede servir para fundamentar otro tipo de derechos - contrarios al principio constitucional de neutralidad religiosa - como sería el caso de un eventual derecho a exigir la autorización siempre y en todo caso de la apertura, o el derecho a la recalificación obligatoria para construir un centro religioso; una hipótesis que ya ha sido declarada incompatible con el Convenio de Roma por la jurisprudencia del TEDH.

La jurisprudencia del TC ha subrayado que para garantizar el pleno ejercicio, en régimen de igualdad, de la libertad religiosa es necesaria una acción positiva de los poderes públicos (STC 46/2001, de 15 de febrero). Este mandamiento 
constitucional puede alcanzar incluso a la configuración de un derecho de crédito que justifique tanto la adopción de medidas regulativas, como la concesión de dotaciones prestacionales que permitan el ejercicio del derecho individualizado o colectivo de la libertad religiosa. De ahí que, en relación con la utilización del suelo o la distribución de la reservas previstas legalmente, para creación de centros de culto, las autoridades municipales deberían tomar en consideración la situación de desigualdad real en la que se encuentran la confesiones minoritarias respecto de la religión socialmente mayoritaria (católica), con objeto de adoptar unos criterios de adjudicación que compensen, o al menos atenúen, esa situación de desequilibrio; se trataría de una forma de cumplir con el principio de «laicidad positiva» en combinación con el principio de igualdad material del artículo 9-2. ${ }^{\circ}$ de la CE.

No hay mención alguna a la dimensión espacial/urbanística de la libertad religiosa en las leyes y tratados que contienen los acuerdos con las diferentes confesiones y comunidades religiosas en España. Este silencio legislativo deja abierta en principio la «vía autonómica» para la regulación legislativa de esta materia, ya que no se imponen ni siquiera condiciones mínimas que deban cumplirse por los poderes públicos de la Comunidad Autónoma.

Hasta ahora, no se han fijado por la legislación urbanística general del Estado, ni en la aprobada en esta materia por las CC.AA. (salvo Cataluña, Ley 16/2009) unas determinaciones o estándares específicos para este tipo de «equipamientos religiosos». Sin embargo, en este momento parece necesario que el legislador competente (estatal o autonómico) proporcione una respuesta positiva a un problema que afecta de lleno a la gobernanza de la diversidad cultural existente en la sociedad española en general.

La regulación que se pueda aprobar en este sentido por las CC.AA. no debería centrarse únicamente en resolver el doble dilema de si hay que reservar espacios para centros de culto y dónde ubicarlos en el planeamiento urbano de los núcleos de población. Hay otra dimensión «sustantiva» que merece tomarse en consideración para una buena gestión del pluralismo religioso. La eventual previsión legislativa de una «reserva urbanística» destinada a uso confesional no garantiza por sí misma el problema de fondo que - como la experiencia demuestra- se manifiesta en forma de oposición social a la implantación de centros de culto de confesiones minoritarias, o la inexistencia de pautas objetivas de reparto del espacio reservado urbanísticamente a ese fin.

La inclusión social o la segregación como criterio «en "negativo" de referencia para los poderes públicos deben orientar como pautas legales vinculantes el diseño de los futuros instrumentos de planeamiento urbano. Para ello, una solución metodológicamente posible sería el establecimiento de directrices legisla- 
tivas dirigidas a las autoridades encargadas de la planificación y la gestión urbanística, en las que se contemplen potenciales usos «pluriconfesionales» (oratorios plurireligiosos o ecuménicos) de los espacios destinados a equipamientos religiosos, y cuando sea posible también la distribución proporcional, razonable y equitativa de esos espacios entre las diversas comunidades religiosas de implantación social, garantizando así el principio de igualdad entre todas ellas.

Ciertamente las eventuales limitaciones que se establezcan en una normativa aprobada por las CC.AA. al ejercicio de la libertad de culto están ya previstas y no podrían ser diferentes a la contempladas en la LOLR y el Convenio Europeo de DH (1950); estos últimos representan cánones insuperables para el legislador autonómico y legitiman la imposición eventual de restricciones al ejercicio «externo» de este derecho fundamental, en base a la necesidad de respetar y garantizar otros derechos y bienes constitucionales (salud, seguridad, orden público, etc. $)^{20}$.

Queda pendiente, no obstante, el problema nada irrelevante de la determinación «de los límites de los límites». Las restricciones no pueden convertirse en coartada para obstaculizar el ejercicio en condiciones de igualdad y libertad real y efectiva de la libertad religiosa, en su dimensión externa o como creación de centros de culto. En la adjudicación de licencias de apertura, es necesario evitar la adopción de criterios de oportunidad política —esto es, que no sean estrictamente jurídicos o reglamentarios- en la concesión de licencias de apertura de centros de culto. El problema puede presentarse en el control de decisiones aparentemente legales, que ocultan sin embargo una excesiva dosis de discrecionalidad administrativa, a partir de la cual se pueden llegar a generar situaciones de discriminación en el tratamiento de las diferentes confesiones o comunidades religiosas. Obviamente este tipo de situaciones requieren la intervención de un arbitraje jurisdiccional que determine si, en efecto, se ha llegado a producir un abuso de la autoridad en el ejercicio de una competencia que debe estar suficientemente «reglada».

20 Asimismo en una esfera material como la educación, cuya gestión y desarrollo legislativo entra dentro de lleno en la competencia exclusiva autonómica, resulta imprescindible para las CC.AA. respetar la doctrina que a los largo de estos años ha ido elaborando el TEDH sobre pluralismo religioso en centros de enseñanza. Un estudio exhaustivo de los casos más representativos de esta problemática se encuentra en E. RELAÑO, «Educational pluralism and freedom of religión: recent decisions of the European Court of Human Rights», en British Journal of Religious Education, vol. 32, No I, January, 2010, 19-29. Igualmente en lo referido a las últimas resoluciones sobre el caso Lausti v.Italia, en Gerardo RUIZ-RICO, «El ejercicio de la libertad religiosa en el sistema de enseñanza desde la reciente jurisprudencia constitucional e internacional», en Revista Europea de Derechos Fundamentales, núm. 17, primer semestre, 2011, pp. 43-59. 
El otorgamiento de la licencia de apertura - y no de obra, a la que se le aplicaría la normativa urbanística al uso — tendría que producirse de forma automática, una vez comprobado el cumplimiento de las condiciones legales y administrativas para la puesta en funcionamiento de un centro de culto. La fiscalización de la Administración competente para la concesión de esa licencia únicamente no puede alcanzar a cuestiones de naturaleza religiosa o a las relativas al nivel de arraigo social de la comunidad que pretenda abrir un centro de culto propio. No obstante, resulta recomendable establecer un parámetro de referencia mínimo que facilite a los poderes públicos municipales aquella decisión administrativa. La fórmula legislativa más simple sería la utilización de los instrumentos registrales (Registro general de Confesiones religiosas del Estado, o en su caso de la Comunidad Autónoma), con los que se delimita el mapa de confesiones religiosas que operan en nuestro país; si bien cabría complementar el criterio anterior con la relación de asociaciones y comunidades religiosas que mantienen algún tipo de relación de colaboración específica con cada Comunidad Autónoma.

Así pues, parece necesario introducir un mecanismo específico en el proceso administrativo/urbanístico de apertura de centros de culto, debido fundamentalmente a las condiciones objetivas en las que se desarrolla esa actividad, en la que entran en juego y pueden quedar afectados de manera negativa otros derechos y principios jurídicos (seguridad y orden público, medio ambiente, salud). La implantación de esa licencia específica de apertura debería servir para precisar y concentrar el procedimiento administrativo, en el que hasta ahora se pueden llegar a aplicar otras normas urbanísticas (legislación de suelo estatal y autonómica, ordenanzas municipales) y medioambientales (RAMINP, legislación sectorial de medio ambiente) que regulan aplicables en este ámbito. Se trata por lo demás de un tipo de intervención pública que no resulta problemática, desde el momento en que el Tribunal Supremo ha aceptado desde hace tiempo (STS de 10 de abril de 1989) la posibilidad de que los Ayuntamientos puedan controlar la apertura de los centros de culto, con el argumento de que «el respeto a los distintos cultos religiosos ha de ser armonizado — artículo 16.1 de la Constitución in fine- con el servicio a otros fines de interés general —art. 103.1 de la Constitución-que la Administración no puede olvidar» ${ }^{21}$.

21 Esta doctrina jurisprudencial del máximo órgano de la justicia ordinaria empieza a fraguarse en la sentencia de 29 de enero de 1980. En otra resolución posterior (STS de 4 de febrero de 1987) el TS insiste en la compatibilidad con el principio de neutralidad religiosa de los poderes públicos, sancionada en el artículo 16.3 de la CE, con el hecho de que se puedan reservar en los instrumentos urbanísticos espacios o lugares destinados al culto. Citadas por J. PONCE, cit. p.46.

Esta tesis jurisprudencial recoge en cierto modo la posición doctrinal mayoritaria, que interpreta el principio de laicidad como la necesaria separación entre Iglesia y Estado, pero de ningún 
Hasta el momento, Cataluña ha sido la única Comunidad que ha aprobado una legislación reguladora de la apertura de lugares de culto. La Ley 16/2009 establece unos parámetros jurídicos objetivos que limiten la excesiva diversidad, e indirectamente también la elevada discrecionalidad de los ayuntamientos a la hora de otorgar licencias de apertura para estos centros religiosos. Con plena cobertura estatutaria (art. 161, EAC), la Generalidad ha aprobado una norma que pretende armonizar el ejercicio individual y colectivo de la dimensión externa de la libertad religiosa con la adopción de aquellas medidas que aseguren la higiene y seguridad en los lugares destinados al culto u otras actividades de naturaleza religiosa.

La metodología implantada por la ley catalana para garantizar ese objetivo consiste en introducir un doble instrumento de control de la Administración que se activa en dos fases. En primer lugar, en la fase de diseño del planeamiento urbano, como obligación legal de los ayuntamientos de prever necesariamente suelos que puedan ser utilizados para este tipo de equipamientos comunitarios; se trata de un elemento necesario e ineludible en cualquier planificación urbanística que viene a generar, indirectamente, un «derecho de prestación» exigible jurídicamente en el supuesto de que no se haya contemplado esas previsiones para este tipo de equipamientos. En segundo lugar, se configura un nuevo mecanismo de autorización para la apertura de aquellos lugares de culto - la licencia municipal de apertura - que cumplan las condiciones técnicas de seguridad, salubridad y medioambientales aprobadas reglamentariamente por el Gobierno para la realización de este tipo de actividad.

En todo caso, la Ley catalana intenta también, en paralelo y simultáneamente, garantizar el cumplimiento por las corporaciones municipales de unas pautas normativas de carácter imperativo que impidan decisiones arbitrarias o discriminatorias a la hora de autorizar la licencia de apertura y funcionamiento de esos centros de culto. Para asegurar esta otra finalidad, el artículo 4.2 enuncia de forma bastante explícita un principio que resulta vinculante para los responsables públicos municipales: «las necesidades y disponibilidades municipales no pueden determinarse en ningún caso en función de criterios que puedan comportar algún tipo de discriminación por motivos religiosos o de convicción». El trato igualitario tiene que inspirar asimismo las decisiones del conjunto de Administraciones públicas sobre el uso esporádico para actividades religiosas de equipamientos o espacios de titularidad pública (art. 2).

modo puede suponer un límite al ejercicio de la libertad de culto o de creencias. Vid. María J. GUTIÉRREZ DEL MORAL, «Laicidad y cooperación con las confesiones en España», en Revista General de Derecho Canónico y Derecho Eclesiástico del Estado, Núm. 15, Octubre, 2007. 
Como balance general de esta excepcional — por ahora - regulación legislativa autonómica, cabe pensar que con ella no se va a solucionar toda la problemática social - y política - que generan con frecuencia las demandas que plantean las minorías religiosas para la apertura de centros de culto. No obstante, debemos reconocer que se ha avanzado bastante en cuanto a la necesaria limitación de la discrecionalidad de los Ayuntamientos, cuando sus actuaciones puedan suponer una restricción efectiva del ejercicio del derecho fundamental. Estas limitaciones competenciales no implicarían una lesión de la garantía constitucional de la autonomía local, ya que la configuración eminentemente legal de esta última admite condicionamientos «proporcionales» de esta naturaleza en las funciones atribuidas estatutariamente y por la legislación básica de régimen local. Por otra parte, la ley asume implícitamente la concepción no «absoluta» de esa libertad fundamental, al prever la necesidad de adaptar la apertura de centros de culto a unos requisitos de carácter técnico con los que se intenta proteger otros bienes constitucionales de interés social (seguridad, salubridad, medio ambiente).

Title:

THE REGIONAL DIMENSION OF RELIGIOUS FREEDOM. THE COMPETENCE FOR THE OPENING OF CULT CENTRES

\section{Summary:}

1. The constitutional silence on a competitive degree in religious matters. 2. The regulation of the «religious fact» in the statutes of autonomy. 3. The «Organic Act» of religious freedom as a compulsory normative frame of reference for the autonomous communities. 3.1. Organic content of the fundamental right and possible margins of regional intervention. 3.2. Rules of international law and agreements of the Kingdom of Spain with religious confessions as limits to the autonomic competences in religious matters. 4. Constitutional and jurisdictional feasibility for a regional legislation on cult centres. 5. The opening of cult centres as a constitutional right of legal settings likely to be regulated by the autonomic Parlaments.

\section{Resumen:}

En este trabajo se analizan las competencias de las Comunidades Autónomas en el ámbito de la libertad religiosa. Concretamente, se estudia la posibilidad de que las Comunidades Autónomas legislen sobre la apertura de centros de culto en su territorio. 


\begin{abstract}
:
This paper discusses the competences of the Autonomous Communities about the religious freedom. Specifically, is studying the possibility of Autonomous Communities to legislate on the opening of cult centres in their territory.
\end{abstract}

Palabras clave:

Libertad religiosa, centros de culto, comunidades autónomas.

Key words:

Religious freedom, cult centres, Autonomous Communities. 
